E3S Web of Conferences 1, 32007 (2013)

DOI: $10.1051 / \mathrm{e} 3$ sconf/20130132007

C) Owned by the authors, published by EDP Sciences, 2013

\title{
Comparison of two measurement methods of dissolved gaseous mercury concentrations and estimations of supersaturation grade and mercury fluxes during a research campaign at the Mediterranean Sea
}

\author{
M. Nerentorp ${ }^{1}$, K. Gårdfeldt ${ }^{1}$ and I. Wängberg ${ }^{3}$ \\ ${ }^{1}$ Department of environmental inorganic chemistry, Chemical and Biological Engineering, Chalmers University of \\ Technology, Kemivägen 4, 41296 Göteborg, Sweden, michelle.nerentorp@chalmers.se, \\ katarina.gardfeldt@chalmers.se \\ ${ }^{3}$ IVL Swedish Environmental Institute, Aschebergsgatan 44, 41133 Göteborg, ingvar.wangberg@ivl.se
}

\begin{abstract}
Dissolved gaseous mercury (DGM) concentrations and gaseous elemental mercury (GEM) concentrations were measured during an oceanographic campaign in the Mediterranean Sea. The DGM concentrations were measured using two different methods, a manual- and an automated method. The manual method was used to obtain DGM depth profiles at several stations throughout the campaign. The automated device measured DGM concentrations continuously at a depth of $4 \mathrm{~m}$. Gaseous elemental mercury (GEM) concentrations in air were measured continuously at the bridge deck. The objectives were to achieve DGM depth profiles, compare the manual- and automated DGM measurement methods, to calculate the supersaturation grades of the sea and the evasional fluxes from the sea surface. Depth profiles of the four measured stations show no diurnal variations. The manual- and the automated method show good compliance. Supersaturation grades are high due to high DGM values and low GEM concentrations. Fluxes of $\mathrm{Hg}$ from the sea surface are more dependent on the wind speed than on the supersaturation grade according to the flux models used.
\end{abstract}

Key words: Mercury, DGM, GEM, Supersaturation grades, Mercury fluxes, Mediterranean Sea.

\section{Introduction}

The heavy metal mercury $(\mathrm{Hg})$ is a naturally occurring element in nature. Natural emissions of mercury from the lithosphere can be allocated to volcanic activity, forest fires, weathering of rocks and evasion of mercury from surfaces. Since the industrialization, anthropogenic emissions have increased the $\mathrm{Hg}$ load in the atmosphere by a factor of three (Mason and Sheu, 2002; Lindberg et al., 2007). Some microorganisms can transform inorganic $\mathrm{Hg}$ into hazardous methyl mercury which can accumulate through the food chain and harm predators (Jensen and Jernelöv, 1969).

Research on reaction- and transportation mechanisms of $\mathrm{Hg}$ in air and water is important in order to understand the environmental effects of rising $\mathrm{Hg}$ concentrations. Mapping concentrations of $\mathrm{Hg}$ species at various locations and seasons helps understanding the complicated cycle of the metal. $\mathrm{Hg}$ in the environment changes between oxidized- and gaseous form. This is an important mechanism regarding accumulation and reemission of mercury to/from the sea surface.
Chalmers is a partner of the five-year long European Commission's project Global Mercury Observation System (GMOS) with several partners all over the world. The overall aim of the GMOS project is to establish a worldwide observation of mercury concentrations in air and water (GMOS- Global Mercury Observation System, 2012).

During the oceanographic campaign Fenice 2011, measurements of $\mathrm{Hg}$ in water and air were performed at the Mediterranean Sea onboard the research vessel Urania. The expedition was allocated to the Tyrrhenian Sea and the overall aim with the cruise was to perform an intercomparison exercise with partners from GMOS. Seven stations were visited and both natural- and contaminated sites were represented, see cruise plan in figure 2. Dissolved gaseous mercury (DGM) at different depths in the sea water was measured manually at several stations. With an automatic device, DGM concentrations were obtained continuously at a depth of approximately 4 $\mathrm{m}$. The two methods were compared for their correspondence. Gaseous elemental mercury (GEM) concentrations in the surrounding air were measured 
continuously during the campaign. Using obtained results, supersaturation grades of the sea and $\mathrm{Hg}$ fluxes from the sea surface could be calculated.

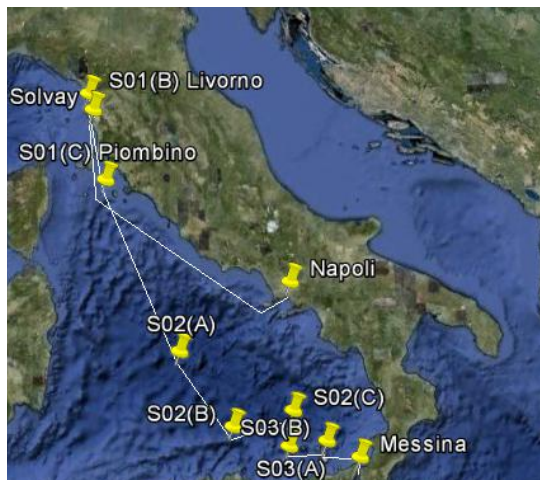

Fig. 1. Stations visited during Fenice 2011.

\section{Materials and Methods}

Measuring DGM during the research campaign was performed with two different methods, a manual system and an automated system. The results of these two methods were later compared. GEM in the surrounding air during the cruise was continously measured and the results of the DGM and GEM measurements were used to calculate supersaturation grades and fluxes of $\mathrm{Hg}$ from the sea surface.

\section{DGM measurements - Manual method}

DGM concentrations were measured in discrete water samples at different depths achieved with a rosette system containing 24 Go-Flo bottles. Water samples of approximately 0.4 liters were tapped into a glass bottle which was transferred to the lab located indoors. The glass bottle with sample was directly connected to the analysis set-up, which consisted of an impinger system. $\mathrm{Hg}$-free air was used to purge the water sample via a glass frit for a period of 9 minutes. The impinger system was directly connected to a Tekran 2537A mercury instrument which analyzed $\mathrm{Hg}$ in the outgoing air. The result of the analysis was recorded using the software TekCap 2537 provided by Tekran Instruments Corporation. The instrument was calibrated in conjunction to the measurements and regular checks of blanks were performed and corrected for. The efficiency and reproducibility of this method has been reported by Gårdfeldt et al. (2002).

\section{DGM measurements - Automated method}

Surface DGM concentrations of the sea water were measured continuously using an opposite flow extractor (Andersson et al., 2008a). The principle of this device is an opposite flow system, where a constant flow of mercury-free air is purged via a glass frit through the continuous inflow of sample water. The system consists of a smaller plexi glass cylinder attached inside a larger one. Into the inner smaller cylinder, a constant flow of sample water is entering the top, leaving in the bottom through holes and entering the outer larger container. From the outer cylinder the water reaches the final outlet that is connected to a sink. Through the glass frit in the bottom of the inner cylinder, a constant flow of $\mathrm{Hg}$-free air is entering the system and used to purge the sample water flowing in the opposite direction. An equilibrium concentration of the $\mathrm{Hg}^{0}$ concentration in the outgoing sample water $\left(\mathrm{C}_{\mathrm{w}}\right)$ is established and is thus represented in the $\mathrm{Hg}^{0}$ equilibrium concentration in the outgoing air in the top of the inner cylinder $\left(\mathrm{C}_{\mathrm{a}}\right)$ according to Henry's law equilibrium, see equation 1.

$$
H^{\prime}=\frac{C_{a}}{C_{w}}
$$

H' is the dimensionless Henry's law constant at the actual water temperature which can be calculated with equation 2 (Andersson et al., 2008b).

$$
H^{\prime}=e^{-2404.3 / T[K]}+6.92
$$

The contact time between the air and the water is important to consider ascertaining that the equilibrium $\mathrm{C}_{\mathrm{a}}$ $\leftrightarrow \mathrm{C}_{\mathrm{w}}$ can be established. The contact time can be adjusted by regulating the flow rate of water $\left(\mathrm{r}_{\mathrm{w}}\right)$ and the air flow rate $\left(r_{a}\right)$.

The sampled seawater was obtained from one of the ship's bow water systems which had an inlet at approximately $4 \mathrm{~m}$ depth. The selected $r_{w}$ and $r_{a}$ were $9 \mathrm{~L}$ $\mathrm{min}^{-1}$ and $1.4 \mathrm{~L} \mathrm{~min}^{-1}$ respectively. The other parameters are $\mathrm{C}_{\mathrm{w}}{ }^{0}$, the DGM concentration in the sea water, $\mathrm{C}_{\mathrm{a}}{ }^{0}$, the mercury concentration in the incoming air which was estimated to be $0.1 \mathrm{pg} \mathrm{L}^{-1}$.

$\mathrm{C}_{\mathrm{a}}$ was measured with the $\mathrm{Hg}$ instrument, Tekran 2537A. The DGM concentration in the sea water was calculated using equation 3 ,

$$
C_{w}^{0}=\frac{C_{a}}{H^{\prime}}+\left(C_{a}-C_{a}^{0}\right) \times \frac{r_{a}}{r_{w}}
$$

which is an adaption of equations presented in Andersson et al. (2008a). The flows of air and water need to be taken into consideration when adjusting the calculations according to equation 3 . The method is further described in Andersson et al. (2008a).

\section{GEM measurements}

Measurements of GEM concentrations were carried out using a Lumex 915+ instrument. A pump, located outside the bridge deck was used to pump outdoor air to the inside where the instrument was located. Values of GEM concentrations were obtained every 5 second.

\section{Results and Discussion}

\section{Depth profiles of DGM - Manual method}

Using a rosette system, samples could be collected from different chosen depths. A depth profile of the station S01C, outside Piombino (42 55, 82N, 010 37,64E) at different times of the day is shown in figure 2 . The depth profiles show no significant diurnal variations at any station examined during the cruise campaign. 


\section{Automated DGM- and GEM measurements}

The results from the automated DGM-method are shown in figure 4. The concentrations are increasing throughout the cruise and show higher values going south.

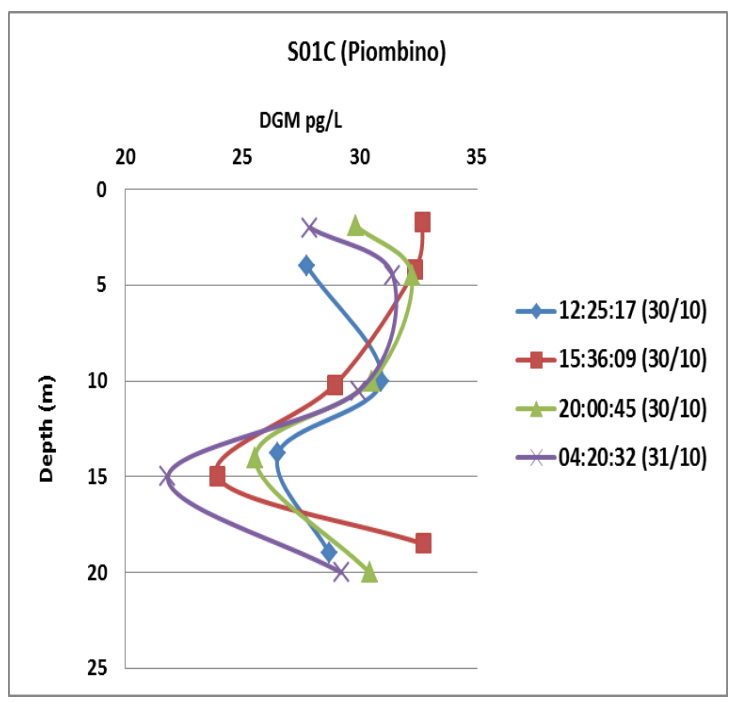

Fig. 2. DGM depth profile of station S01C.

\section{Automated DGM- and GEM measurements}

The results from the automated DGM-method are shown in figure 4. The concentrations are increasing throughout the cruise and show higher values going south.

The GEM measurements show a different trend. It shows higher values in the beginning when visiting contaminated sites and further on it slightly decreases and kept almost constant. The GEM results are shown in figure 4 .

Comparison of automated method and manual method for DGM measurements

The results of the discrete samples at $4 \mathrm{~m}$ depth analyzed manually were compared with the results of the automated method. Some comparison points are shown in figure 3 . The results show that the manual and the automated method almost agree even though the manual method mostly shows a somewhat higher value.

\section{Supersaturation grade and fluxes}

The results of the automated DGM- and GEM measurements were used to calculate the supersaturation grade of the sea water according to equation 4 ,

$$
S=100 \times \frac{C_{W}^{0}}{G E M} \times H^{\prime}
$$

Where $\mathrm{S}$ is the supersaturation grade $[\%], \mathrm{C}_{\mathrm{w}}{ }^{0}$ is the DGM concentration in the sea water calculated with equation 3, GEM is the results obtained with Lumex 915+ and H' is Henry's law constant calculated with equation 2. Due to high DGM concentrations in the sea water compared to low GEM concentrations, the supersaturation grades are high. The results of the supersaturation grades are shown in figure 2 .

The spatial resolved evasional flux of gaseous mercury from the water surface was estimated using gas exchange models developed by Wanninkhof (1992) and Nightingale et al. (2000). The calculations are further described by Andersson et al. (2007) and the results of the calculations are displayed in figure 4. Due to the factors in the equations developed by Wanninkhof (1992), the evasional flux is highly dependent on the wind speed and show direct correlations.

\section{Conclusion}

The manual and the automated method used to measure DGM concentrations correspond well and are both comprehensive methods measuring DGM during research campaigns at sea.

The supersaturation grades are high due to substantially differences in GEM and DGM concentrations in the Mediterranean Sea. The flux calculations show only a slightly correlation with supersaturation grades since its dependence with wind speed is more influencing according to Wanninkhof's and Nightingale's equations (Wanninkhof, 1992; Nightingale et al., 2000).

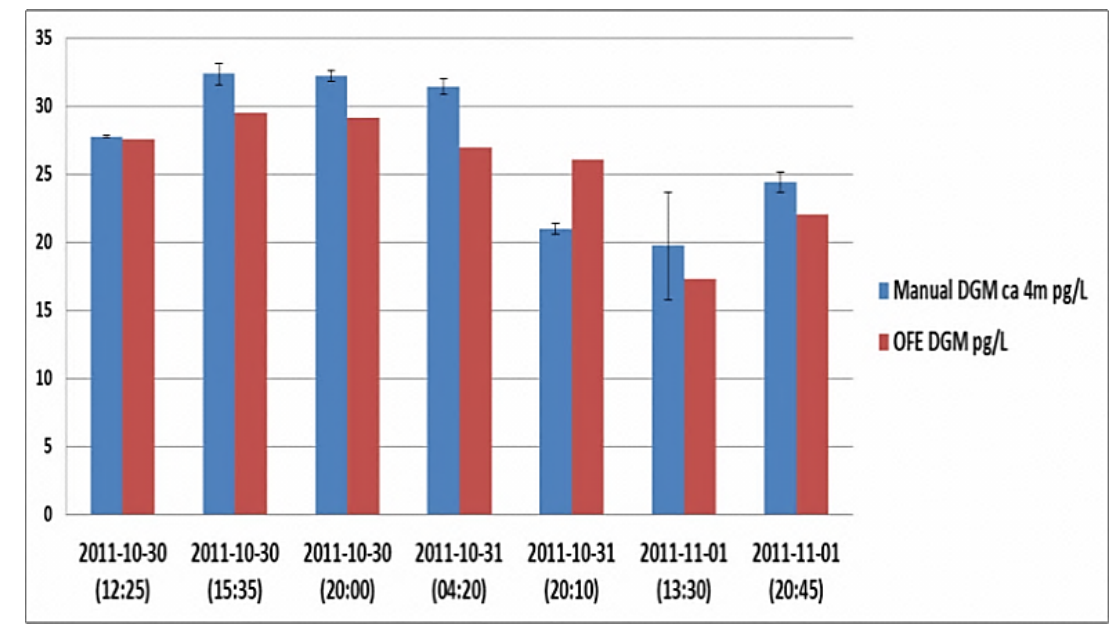

Fig. 3. Intercomparison of manual- and automated DGM measurement method 


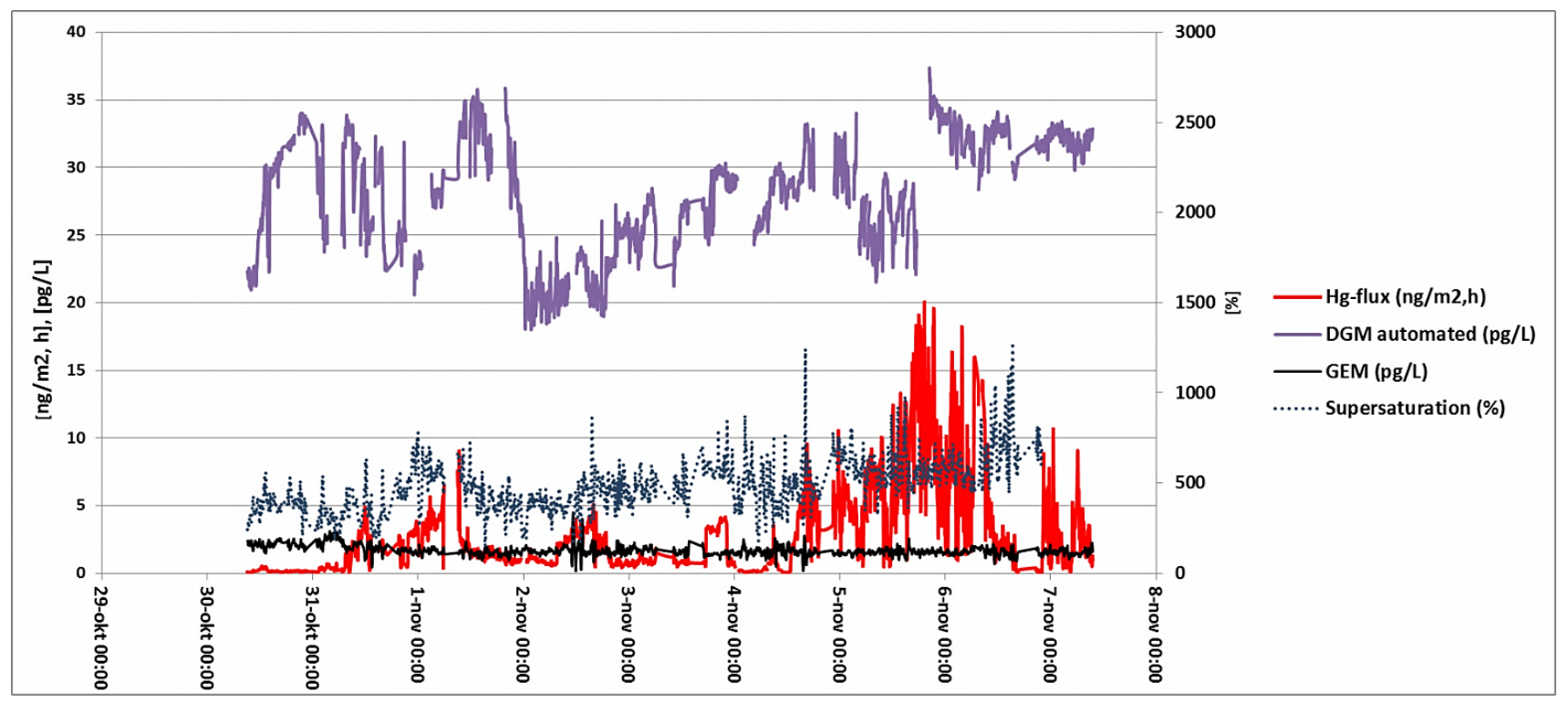

Fig. 4. The results of the automated DGM- and GEM concentration measurements. Also displayed are the results of calculations of the supersaturation grades and the mercury evasional fluxes from the sea surface.

\section{Acknowledgements}

The authors would like to thank the partners of the GMOS-project, the National Research Council (CNR) for the initiative and funding of the research campaign Fenice 2011 and the crew members of the research vessel Urania.

\section{References}

Andersson ME, Gårdfeldt K, Wängberg I, Sprovieri F, Pirrone N, Lindquist $O$. Seasonal and daily variation of mercury evasion at coastal and off shore sites from the Mediterranean Sea. Marine Chemistry 2007;104:214-226.

Anderson ME. Transport of mercury species in the environment-exchange between oceanic waters and the atmosphere. Ph.D. thesis. Department of Chemistry, Gothenburg University 2008.

Andersson ME, Gårdfeldt K. Wängberg I. A description of an automatic continuous equilibruim system for measurement of dissolved gaseous mercury. Analytical and Bioanalytical Chemistry 2008a; 391:2277-2282.

Andersson ME, Gårdfeldt K. Wängberg I. Strömberg D. Determination of Henry's law constant for elemental mercury. Chemosphere 2008b; 73:587592.
GMOS- Global Mercury Observation System. [online]. Available at: www.gmos.eu. (Accessed 2012-02-13)

Gårdfeldt K, Horvat M, Sommar J, Kotnik J, Fajon V, Wängberg I, Lindquist $O$. Comparison of procedures for measurements of dissolved gaseous mercury in seawater performed an a Mediterranean cruise. Analytical and Bioanalythical Chemistry 2002; 374:1002-1008.

Jensen S, Jernelöv A. Biological methylation of mercury in aquatic organisms. Nature 1969; 223:753-754.

Lindberg S, Bullock R, Ebinghaus R, Engstrom D R, Feng X, Fitzgerald W F, Pirrone N, Prestbo E, Seigneur C. A synthesis of progress and encertainties in attributing the sources of mercury in deposition. Ambio 2007; 36(1):19-32.

Mason, R P, Sheu G R. Role of the Ocean in the global mercury cycle. Global biogeochemical cycles 2002; 16(4):40-1-40-14.

Nightingale PD, Malin G, Law CS, Watson AJ, Liss PS, Liddicoat MI, Boutin J, Upstill-Goddard RC. In situ evaluation of air-sea gas exchange parameterization using novel conservative and volatile tracers. Global Biogeochemical Cycles 2000; 14:373-387.

Wanninkhof R. Relationship between wind speed and gas exchange over the ocean. Journal of Geophysical Research 1992; 97:7373-7382. 